\title{
Correlation of Genomic and Pedigree Inbreeding Coefficients in Small Cattle Populations
}

\author{
José Cortes-Hernández ${ }^{1}{ }^{\mathbb{D}}$, Adriana García-Ruiz ${ }^{1}{ }^{\mathbb{D}}$, Carlos Gustavo Vásquez-Peláez $^{2}$ \\ and Felipe de Jesus Ruiz-Lopez ${ }^{1, *(D)}$ \\ 1 Centro Nacional de Investigación Disciplinaria en Fisiología y Mejoramiento Animal, Instituto Nacional de \\ Investigaciones Forestales Agrícolas y Pecuarias, Km 1 Carretera a Colón, Ajuchitlán Colón, C.P., \\ Querétaro 76280, Mexico; jgch1992@hotmail.com (J.C.-H.); garcia.adriana@inifap.gob.mx (A.G.-R.) \\ 2 Departamento de Genética y Bioestadística, FMVZ-UNAM, Ciudad Universitaria, Av. Universidad \#3000, \\ Colonia C.U., Ciudad de México 04510, Mexico; carlosgv@unam.mx \\ * Correspondence: ruiz.felipe@inifap.gob.mx
}

check for updates

Citation: Cortes-Hernández, J.; García-Ruiz, A.; Vásquez-Peláez, C.G.; Ruiz-Lopez, F.d.J. Correlation of Genomic and Pedigree Inbreeding Coefficients in Small Cattle

Populations. Animals 2021, 11, 3234. https://doi.org/10.3390/ani11113234

Academic Editor: Armin Schmitt

Received: 7 October 2021

Accepted: 10 November 2021

Published: 12 November 2021

Publisher's Note: MDPI stays neutral with regard to jurisdictional claims in published maps and institutional affiliations.

Copyright: (C) 2021 by the authors. Licensee MDPI, Basel, Switzerland. This article is an open access article distributed under the terms and conditions of the Creative Commons Attribution (CC BY) license (https:/ / creativecommons.org/licenses/by/ $4.0 /)$.
Simple Summary: This study aimed to evaluate the consistency of different methodologies and sources of information used to estimate inbreeding coefficients in small populations by analyzing the correlation between them in the Holstein population of Mexico and to choose the best option in order to aid breeding programs to improve the productive traits of Holstein cattle in smallspecialized populations.

Abstract: This study aimed to identify inbreeding coefficient $(\mathrm{F})$ estimators useful for improvement programs in a small Holstein population through the evaluation of different methodologies in the Mexican Holstein population. F was estimated as follows: (a) from pedigree information (Fped); (b) through runs of homozygosity (Froh); (c) from the number of observed and expected homozygotic SNP in the individuals (Fgeno); (d) through the genomic relationship matrix (Fmg). The study included information from 4277 animals with pedigree records and 100,806 SNP. The average and standard deviation values of $F$ were $3.11 \pm 2.30$ for Fped, $-0.02 \pm 3.55$ for Fgeno, $2.77 \pm 0.71$ for Froh and $3.03 \pm 3.05$ for Fmg. The correlations between coefficients varied from 0.30 between Fped and Froh, to 0.96 between Fgeno and Fmg. Differences in the level of inbreeding among the parent's country of origin were found regardless of the method used. The correlations among genomic inbreeding coefficients were high; however, they were low with Fped, so further research on this topic is required.

Keywords: Holstein cattle; inbreeding coefficient; runs of homozygosity

\section{Introduction}

For many years, the Holstein breed has dominated the dairy industry. Artificial insemination, which has been intensively used in dairy cattle since the 1980s [1], along with embryo transfer, are useful tools in genetic improvement that have increased the rate of genetic progress, decreased generation intervals, increased selection accuracy and reduced the costs of progeny testing [2]. All this, plus the use of genomic information has resulted in the selection of the next generation of animals from a reduced number of families or individuals with high genetic values [3], increasing inbreeding and, therefore, decreasing the effective population size. Furthermore, selection increases the frequency of homozygous regions in the genome, while at the same time decreasing the genetic diversity and affecting the phenotypic values for some productive features (inbreeding depression), lowering the yield per animal [4].

In small livestock populations, one of the most significant problems is the increase in inbreeding, the estimation of which is difficult and sometimes unreliable because of the lack of pedigree records [5]. 
The inbreeding coefficient $(\mathrm{F})$ is defined as the probability that at any locus of an individual, genes identical by descent are found [6]; in other words, it is the replica of a gene at the moment the embryo is generated from two parents with one or more common ancestors [6].

Inbreeding coefficients can be estimated from different sources of information. Wright, in 1922 [6], stipulated a methodology based on pedigree information (Fped), where one obtains the probability of finding, at any locus of an individual, two identical copies of alleles coming from the same ancestral gene via both parental pathways; these are known as identical by descent genes. The estimation of that cumulative probability or inbreeding coefficient is calculated over all the common ancestors in the genealogy of an individual [7].

Recently, other methodologies based on the use of genetic markers in the DNA have been developed to estimate inbreeding coefficients; for example, one calculated with regions or runs of homozygosity (Froh; [8]), the genomic inbreeding coefficient (Fgeno; [9]), or the inbreeding estimated from the genomic relationship matrix (Fmg; [10]).

Runs of homozygosity $(\mathrm{ROH})$ are contiguous DNA lengths of homozygotic genotypes present in an individual's genome due to ancestors transmitting identical haplotypes from one generation to another. These regions can provide information about the level of inbreeding of an individual, its ancestry and the population it belongs to [11].

The $\mathrm{ROH}$ represent genomic homozygosity as a consequence of mating genomically related individuals; additionally, they may be able to reveal the regions that affect the fitness of an individual. Furthermore, these regions caused by inbreeding as an outcome of selection, increase the probability of undesirable recessive alleles being expressed [12]. Nevertheless, $\mathrm{ROH}$ can also be present due to unusual mutations, linkage disequilibrium, or a low recombination rate at certain genomic regions, sometimes resulting in a higher susceptibility to recessive illness [11].

The Fgeno is an inbreeding coefficient equivalent to Wright's within-subpopulation fixation index. Values can range from -1 to +1 . Negative numbers refer to outbreeding present in mating between individuals of different populations or less heterozygous than the population average. Positive values indicate the level of inbreeding of individuals of the same population [13].

The Fmg combines pedigree information with that from molecular makers. When only pedigree information is available, the offspring is assumed to randomly receive one-half of each parent's genes. With the addition of genomic data, one can determine the proportion of the genes received from its ancestors, or in the case of individuals that share no known common ancestors, the proportion of common genes can be determined [14].

Inbreeding has effects on animal health and productivity, hence the possibility of using it as a tool to improve such characteristics. Nowadays, different options are available to estimate $\mathrm{F}$, hence the importance of knowing if they are providing the same information.

One would expect that genomic information would provide a more accurate determination of the level of inbreeding in any individual compared to determination by pedigree. However, not all inbreeding is equal or expected to have adverse effects on fitness. More recent inbreeding is sometimes more detrimental to the productive and reproductive traits of cattle than ancestral inbreeding. In addition, there may be past inbreeding that is not detected with pedigree information that can be calculated through genomic inbreeding coefficients [15].

The aim of this study was to identify inbreeding coefficient (F) estimators in a small Holstein population that could be used in genetic improvement programs. Inbreeding coefficients were calculated using different methodologies and sources of information such as runs of homozygosity (Froh) in different lengths, genomic inbreeding coefficients (Fgeno), the genomic relationship matrix (Fmg) and pedigree information (Fped). Correlations among Froh, Fgeno, Fped and Fmg in the Mexican Holstein population were calculated. The behavior of inbreeding coefficients, based on the origin of the evaluated individuals' parents, was calculated with the objective of evaluating the differences in $\mathrm{F}$ when the germplasm came from different countries and whether the different measures 
were capable of identifying such inbreeding equally among the methods of F. The Froh was also calculated utilizing lengths of $\mathrm{ROH}$ from 1 to $2 \mathrm{Mb}, 2$ to $4 \mathrm{Mb}, 4$ to $8 \mathrm{Mb}, 8$ to $16 \mathrm{Mb}$ and $>16 \mathrm{Mb}$ to identify the length of $\mathrm{ROH}$ that is best associated with Froh with the other coefficients of inbreeding.

\section{Materials and Methods}

To estimate Fped, information based on pedigree was used, which included 212,665 Holstein animals. The number of equivalent complete generations was calculated to estimate the depth of the pedigree using the Pedig software [16]. To estimate Fped, the recursive modified algorithm which takes into account inbreeding different from zero when the parents were unknown and is included in the program INBUPGF90 [17] was used.

For the estimation of Fgeno, Froh and Fmg, 5918 genotypes of Holstein cows from the Mexican population were used. These were distributed in 36 herds and each animal included genomic information of 100,806 SNP markers previously imputed with FindHap V2, VanRaden, USDA, USA [18]. Genotype quality control was applied and genotypes of animals with a call rate $<0.90$ were excluded. For SNP, markers with minor allele frequency (MAF) $<0.02$, call rate $<0.90$ or $p$-value for Hardy-Weinberg $<0.0001$ were excluded.

To define $\mathrm{ROH}$, all runs with a minimum length of $1 \mathrm{Mb}$ and at least $10 \mathrm{SNP}$ were included. With these parameters, the risk of including short $\mathrm{ROH}$ was avoided, which can be frequent because of linkage disequilibrium (DL) [11]; additionally, one heterozygote SNP per run, five missing genotypes, a minimum density of 1 SNP by $100 \mathrm{~kb}$ and a maximum gap between SNP of $500 \mathrm{~kb}$ were allowed [19].

To calculate Froh, the methodology used was that proposed by Mcquillan [8], which considers $F_{\text {roh }}^{i}=\Sigma L_{\text {roh }}^{i} / L_{\text {auto }}$, where $F_{\text {roh }}^{i}$ is the inbreeding coefficient of the individual $i$ calculated with $\mathrm{ROH} ; \Sigma L_{r o h}^{i}$ is the total sum of the ROH segments of an individual $i$ above a specified minimum length, $>1 \mathrm{Mb}$ in this case; $L_{\text {auto }}$ is the length of the autosomal genome covered by SNPs, including centromeres.

The $G$ matrix was calculated using the following formula: $G=\frac{Z Z^{\prime}}{2 \sum P(1-P)}$, where $Z$, is a matrix containing the subtraction of a base population allele frequency from the given marker values and $p$ is the uniform base population allele frequency set at 0.5 due to the fact that the Fmg is better calculated with this allele frequency than estimating it from a base population and $[20,21]$. The program PREGSF90 from the BLUPF90 v1.70 software (University of Georgia, Athens, GA, USA) was used to calculate G [22]. Fmg was calculated as the diagonal of $\mathrm{G}$ minus 1 [20].

To estimate Fgeno, the following formula was used: $f_{g e n o}=\frac{H O-H E}{N M-H E}$, where $\mathrm{HO}$ is the number of observed homozygotic markers; HE is the number of expected homozygotes; $\mathrm{NM}$ is the number of markers in each individual [13].

The analyses of $\mathrm{ROH}$ and Fgeno were performed with the bioinformatics platform Golden Helix ${ }^{\circledR}$ Variation Suite v.8.8.3., Bozeman, MT, USA [23].

The comparisons between the different estimated inbreeding coefficients were made through the estimation of Pearson's correlations [24] among coefficients [25], including only the 4277 animals with all four estimations in the analysis (Fgeno, Fped, Froh and Fmg).

In addition, the correlations of Fgeno, Fped, and Fmg with Froh calculated with different $\mathrm{ROH}$ lengths were evaluated, with the aim of determining which length of $\mathrm{ROH}$ to calculate the Froh was best associated with the inbreeding coefficients. The RHO lengths studied were divided into five classes, from 1 to $2 \mathrm{Mb}, 2$ to $4 \mathrm{Mb}, 4$ to $8 \mathrm{Mb}, 8$ to $16 \mathrm{Mb}$ and $>16 \mathrm{Mb}$, and included 3759 animals out of the total 4277 because animals that did not have the four inbreeding coefficients of the five classes were eliminated.

Additionally, to evaluate the relationship between inbreeding and country of origin of the animal's parents used in this study and the influence in the population, analyses were performed for countries of origin of sires and dams with more than 20 progenies in Mexico.

It might be expected that the progeny of parents from different countries would have different levels of inbreeding depending on the level of selection in each country of origin, and different expectations of future inbreeding due to the different participation 
of exporting countries in the genetic makeup of the population, but it is of interest to determine if the different methods for calculating F can better identify the changes in each group of animals.

Finally, the trends of the four inbreeding coefficients by birth year from 2005 to 2017 were evaluated. To prevent problems due to the difference in scales between the birth years and the inbreeding coefficients, birth years were assigned values from 1 to 13. Polynomial regressions [26] were fit to the inbreeding coefficients with the $R$ v3.6.1 [27] software, $R$ Foundation for statistical computing, Vienna, Austria.

\section{Results and Discussion}

\subsection{Fped and Its Relation with Genomic Inbreeding Coefficients}

The number of complete generations calculated with the Pedig Software [16] was seven generations, and the Fped value calculated for this population was $3.11 \pm 2.30 \%$ (Table 1), which is lower than published values in other populations of the same breed. In Spain, an average of $4.2 \%$ was reported [3] and $4.4 \%$ in the case of Italy [28].

Table 1. Average inbreeding coefficient $(\mathrm{F} \% \pm \mathrm{SD})$ and correlations $( \pm \mathrm{SE})$ among the inbreeding calculation methods (below diagonal; $p<0.0001$ ).

\begin{tabular}{ccccc}
\hline F\% & Fped & Fgeno & Froh & Fmg \\
& $\mathbf{3 . 1 1} \pm \mathbf{2 . 3 0}$ & $\mathbf{- 0 . 0 2} \pm \mathbf{3 . 5 5}$ & $\mathbf{2 . 7 7} \pm \mathbf{0 . 7 1}$ & $\mathbf{3 . 0 3} \pm \mathbf{3 . 0 5}$ \\
\hline Fped & 1 & & & \\
Fgeno & $0.39 \pm 0.013$ & 1 & & \\
Froh & $0.30 \pm 0.014$ & $0.82 \pm 0.005$ & 1 & \\
Fmg & $0.41 \pm 0.013$ & $0.96 \pm 0.001$ & $0.82 \pm 0.005$ & 1 \\
\hline
\end{tabular}

F\%: inbreeding coefficient in percentage, Fped: Inbreeding coefficient calculated through pedigree, Fgeno: Inbreeding coefficient calculated by the number of homozygotic SNP markers observed and expected, Fmg: Inbreeding coefficient calculated through genomic relationship matrix. Froh: Inbreeding coefficient calculated by runs of homozygosity, Number of observations with all coefficients: 4277, SD: Standard deviation, SE: Standard error.

Fgeno values averaged $-0.02 \pm 3.55 \%$, values that were low compared to Fped. The correlation between Fped and Fgeno was 0.39 , a relationship similar in comparison to the one reported in Holstein bulls in China, where Zhang et al. [29] determined a correlation of 0.38 .

The correlation between Fped and Froh was low (0.30) compared with other studies, where correlations were of 0.82 [29] between these coefficients, with a minimum of 20 SNP per RHO have been found. The discrepancies between the results of different studies can be due to differences in the structure of the populations, the parameters used to define $\mathrm{ROH}$, the accuracy and depth of the pedigrees or the effect of $\mathrm{ROH}^{\prime}$ s length, a topic that will be dealt with later in this paper.

In this study, the correlation calculated between Fped and Fmg was of 0.41 . In the study conducted by Zhang et al. [29], a negative but not significant correlation (-0.20) between these coefficients was reported in the same cattle breed of our study; additionally, in the same study, the author calculated correlations of $-0.18(p<0.01)$ for Jersey cattle and $0.36(p<0.01)$ for the Danish Red, a Danish native breed; the authors attributed the moderate correlation in the Danish Red to the fact that this breed has a heterozygosity level that is higher than the Jersey or Holstein breeds.

\subsection{Froh and the Genome Proportion with $\mathrm{ROH}$}

The average length of the $\mathrm{ROH}$ was $4.8 \pm 0.78 \mathrm{Mb}$ with a minimum length of $1.54 \mathrm{Mb}$ and a maximum of $100.56 \mathrm{Mb}$, and an average number of $47 \pm 10.73 \mathrm{ROH}$ per animal. The average length of the genome covered by $\mathrm{ROH}$ was $276.89 \mathrm{Mb}$ for the population in this study, similar to that of Holstein cattle in the USA, where two studies demonstrated a covered genome's length of 290.6 Mb and 299.6 Mb [30,31], which could be the reason for a higher estimation of the inbreeding degree for animals descending from dams of USA 
origin. This may be because the registered Holstein population of Mexico presents a high genetic relationship with the population in the USA [32].

The Froh calculated in this study was $(2.72 \pm 0.71 \%)$ which is lower than the one calculated for Holstein cattle from Italy and the USA, $3.8 \pm 2.1 \%$ and $4.2 \pm 2.3 \%$, respectively [5]. On the other hand, higher Froh values have been published by Rodríguez-Ramilo et al. [3] in Holstein animals from Spain (7.7\%). The differences in Froh estimates can be attributed mainly to the effective size of the population, missing pedigree information or the definitions of $\mathrm{ROH}$ used $[5,21]$. Froh is a good estimator of the homozygosity in the genome of each individual but has its disadvantages when calculating the homozygosity in the population based on low-density arrays due to the relationship between density and the length of the ROH determined [33].

\subsection{Froh with Different Lengths of $\mathrm{ROH}$ and Its Relationship with Other Inbreeding Coefficients}

The largest proportion of $\mathrm{ROH}$ found were those from 1 to $2 \mathrm{Mb}$ with $51.32 \%$, followed by those of 2 to $4 \mathrm{Mb}$ with $22 \%$, with the least being those greater than $16 \mathrm{Mb}$ with $15 \%$ (Table 2). The highest number of short $\mathrm{ROH}$ is related to ancient inbreeding [28].

Table 2. Number and percentage of $\mathrm{ROH}$ by length.

\begin{tabular}{ccc}
\hline Length $\mathbf{M b}$ & No. $\mathbf{R O H}$ & $\%$ \\
\hline $1-2$ & 215,175 & 51.32 \\
$2-4$ & 93,596 & 22.32 \\
$4-8$ & 61,329 & 14.63 \\
$8-16$ & 34,375 & 8.20 \\
$>16$ & 14,812 & 3.53 \\
\hline
\end{tabular}

Mb: Megabase, ROH: Runs of Homozygosity.

The correlation calculated between Froh and Fgeno was 0.82, higher than the results reported by Zhang et al. [29] who found a correlation of 0.61 between the same coefficients. Mastrangelo et al. [5] reported higher correlation values between Froh and Fgeno (0.89), similar to the ones found in this study, and the authors attributed this to recent inbreeding in the Italian Holstein population.

Table 3 shows the correlation coefficients between Fgeno and Fped with Froh with different lengths of $\mathrm{ROH}$. The correlations increased for all coefficients as $\mathrm{ROH}$ lengths increased, particularly when the runs were higher than $16 \mathrm{Mb}$.

Table 3. Correlations $( \pm \mathrm{SE})$ among the inbreeding coefficients between Fgeno, Fmg and Fped with Froh with different lengths of $\mathrm{ROH}$.

\begin{tabular}{|c|c|c|c|c|c|}
\hline \multicolumn{6}{|c|}{ Froh with Different Lengths of ROH } \\
\hline & $\begin{array}{c}1-2 \mathrm{Mb} \\
\text { (Froh 1-2) }\end{array}$ & $\begin{array}{c}2-4 \mathrm{Mb} \\
(\text { Froh } 2-4)\end{array}$ & $\begin{array}{c}4-8 \mathrm{Mb} \\
\text { (Froh } 4-8 \text { ) }\end{array}$ & $\begin{array}{c}8-16 \mathrm{Mb} \\
\left.\text { (Froh }{ }_{8-16}\right)\end{array}$ & $\begin{array}{l}>16 \mathrm{Mb} \\
(\text { Froh }>16)\end{array}$ \\
\hline $\mathrm{N}^{\circ}$ of animals & & & 3759 & & \\
\hline Fgeno & $-0.01 \pm 0.016$ & $0.14 \pm 0.016^{*}$ & $0.30 \pm 0.015^{*}$ & $0.46 \pm 0.013 *$ & $0.71 \pm 0.008^{*}$ \\
\hline Fped & $-0.03 \pm 0.016$ & $-0.02 \pm 0.016$ & $0.05 \pm 0.016$ & $0.15 \pm 0.016^{*}$ & $0.34 \pm 0.014 *$ \\
\hline Fmg & $0.01 \pm 0.016$ & $0.16 \pm 0.016^{*}$ & $0.30 \pm 0.015^{*}$ & $0.46 \pm 0.013 *$ & $0.69 \pm 0.008 *$ \\
\hline
\end{tabular}

Mb: Megabase, ROH: Runs of homozygosity, Fmg: Inbreeding coefficient calculated through genomic relationship matrix, Fgeno: Inbreeding coefficient calculated from the number of homozygotic SNP markers observed and expected, Froh: Inbreeding coefficient calculated from the number of Homozygotic SNP markers, Fped: Inbreeding coefficient calculated through pedigree, SE: Standard error, ${ }^{*}$ Statistically significant correlations $(p<0.0001)$.

The correlation between Froh calculated with different lengths of $\mathrm{ROH}$ with the other coefficients increased when the length of the runs was greater than $2 \mathrm{Mb}$ for Fgeno and Fmg, and with Fped increased when the length of the runs was greater than $8 \mathrm{Mb}$ (Table 3). Makanjuola et al. [34] reported similar results in a study of Canadian Holstein cattle, with increasing correlations between Froh and Fmg from $\approx 0.20$ with Froh $2-4$ to $\approx 0.70$ with Froh $>16$. The trends in the correlation between Fped with Froh calculated with the different lengths of $\mathrm{ROH}$ was similar to that reported by Makanjuola et al. [34] who 
found correlations with a negative level $(\approx-0.10)$ with Froh $_{1-2}$ and positive correlations $(\approx 0.40)$ with Froh $>16$. However, they did not find the same correlation trend between Froh (calculated with the five ROH lengths) with Fped (calculated with seven generations of common ancestors) probably because the pedigree only includes ancient inbreeding.

In contrast, a simulation study in a population of 1000 individuals, Caballero et al. [35] reported a correlation of 0.66 between Froh and Fgeno when the length of the $\mathrm{ROH}$ was greater than $5 \mathrm{Mb}$, and of 0.82 when the length of the $\mathrm{ROH}$ was greater than $1 \mathrm{Mb}$. The authors suggested that this could be explained because short ROH may not fully reflect the proportion of the genome which is identical by descent, overestimating the true genomic inbreeding.

Ferenčaković et al. [13] reported a similar trend as the one found in this study. They calculated a correlation between Froh and Fped of 0.50 with $\mathrm{ROH}>1 \mathrm{Mb}$ and 0.66 with $\mathrm{ROH}>16 \mathrm{Mb}$ in Brown Swiss cattle. The increased correlation in our study can probably be attributed to the fact that the population shows recent inbreeding (Figures 1 and 2), confirmed by the frequency of large RHO [29]. Gurgul et al. [36] obtained a low correlation between Fped and Froh (0.295) with an $\mathrm{ROH}$ length of $4 \mathrm{Mb}$ with five pedigree generations and found even lower correlations (0.243) when $\mathrm{ROH}$ were longer than $16 \mathrm{Mb}$, explaining that the relationship between Fped and Froh could be affected by the number of generations included in the pedigree since Froh with long $\mathrm{ROH}$ reflects the recent inbreeding of animals.

\subsection{Fmg and Its Relationship with the Other Inbreeding Coefficients}

The correlation found between Fmg and Fgeno (0.96) was higher than the one obtained between Fmg and Fped (0.41), because Fmg and Fgeno use individual genetic markers for their estimation while Fped does not utilize genomic information. The correlation reported between Fmg and Froh has been very variable. While the correlation found in this study was high (0.82), and was different from Mastrangelo et al. [5], who calculated Fmg values of 0.042 in Italy's Holstein cattle and a non-significant correlation with Froh of 0.18. Bjelland et al. [21] estimated a correlation between Fmg and Froh similar to ours which was 0.81 in the USA's Holstein cattle. Caution should be exercised when using Fmg because Villanueva et al. [37] mentioned that Fmg can lead to inconsistent results in terms of the gain and loss of genetic variability, and, thus, to misleading interpretations, and do not always provide a useful measure of inbreeding.

\subsection{Fgeno and the Possibility of Mating with Different Populations}

In this study, Fgeno had a negative estimate similar to that found by Mastrangelo et al. [5] who reported values for Fgeno of $-1.4 \%$ in Italy's Holstein breed. Of the analyzed animals, $2361(55.20 \%)$ had a negative value for Fgeno, with an average of $-2.34 \%$, a value that could indicate that the estimated population comes from distant families or because the animals are more heterozygous than the population average [13].

\subsection{Influence of the Origin Parents' Country on The Level of Inbreeding in the Offspring}

Table 4 analyzes the influence of the parent's country of origin, showing the inbreeding coefficient values for animals with positive Fgeno, Fped, Froh and Fmg (1852 animals), comparing animals with parents from Canada (CAN), the United States of America (USA), the Netherlands (NLD) and Mexico (MEX).

Animals that descended from parents from NLD showed lower values of Fgeno $(2.22 \pm 1.92 \%)$ than the rest, probably due to the reduced number of animals descending from these parents in the pedigree and the fact that they come from a more genetically distant population in the study. On the other hand, animals with Mexican parents had the highest Fped ( $4.87 \pm 3.46 \%$ ), which could be attributed to the intensive use of local animals inside the population or in particular subpopulations.

Van Doormaal, in 2016, cited by Andere et al. [38], reported an Fped value in a Holstein cattle population from Canada of $7.10 \%$, which is higher than the one found in this study $(3.48 \%)$ for animals descending from Canadian parents; which, altogether with 
the results obtained for Froh (3.40\%) and Fgeno (2.95\%), suggests a higher inbreeding average for Canadian parent's offspring compared to the other countries in this study with the exception of Mexico.

Table 4. Inbreeding coefficients in $\%( \pm \mathrm{SE})$ for animals with positive Fgeno, grouped by sire and dam's country of origin.

\begin{tabular}{cccccc}
\hline $\begin{array}{c}\text { Sire's Country } \\
\text { of Origin }\end{array}$ & No of Calves & Fgeno & Fped & Froh & Fmg \\
\hline MEX & 405 & $3.35 \pm 0.19$ & $4.87 \pm 0.16$ & $3.07 \pm 0.04$ & $5.60 \pm 0.19$ \\
USA & 1095 & $2.69 \pm 0.08$ & $3.33 \pm 0.08$ & $3.31 \pm 0.02$ & $5.31 \pm 0.07$ \\
CAN & 282 & $2.95 \pm 0.16$ & $3.48 \pm 0.15$ & $3.40 \pm 0.04$ & $5.55 \pm 0.15$ \\
NLD & 67 & $2.22 \pm 0.23$ & $3.55 \pm 0.23$ & $3.18 \pm 0.06$ & $4.99 \pm 0.21$ \\
Dam's country & & & & & \\
of origin & 1599 & $2.85 \pm 0.07$ & $3.68 \pm 0.07$ & $3.26 \pm 0.02$ & $5.38 \pm 0.07$ \\
MEX & 32 & $2.33 \pm 0.34$ & $4.36 \pm 0.38$ & $3.17 \pm 0.10$ & $5.13 \pm 0.29$ \\
USA & 23 & $3.11 \pm 0.53$ & $3.39 \pm 0.48$ & $3.19 \pm 0.14$ & $5.85 \pm 0.47$ \\
CAN & & &
\end{tabular}

Only values for groups with more than 20 calves are shown. MEX: Mexico, USA: United States of America, CAN: Canada, NLD: Netherlands. Fped: Inbreeding coefficient calculated through pedigree, Fgeno: Inbreeding coefficient calculated by the number of homozygotic SNP markers observed and expected, Froh: Inbreeding coefficient calculated from runs of homozygotic, Fmg: Inbreeding coefficient calculated through the genomic relationship matrix.

The descendants from CAN or the USA presented higher Froh values than animals with ancestors from Mexico. This could be because in these countries the intensity of selection is greater than in Mexico. García-Ruiz et al. [39] reported an increase in the inbreeding calculated by pedigree from $4.3 \%$ in the year 2000 to $5.8 \%$ in the year 2010 in Holstein cattle from the USA, and from $5.8 \%$ to $6.4 \%$ in sires, which reflects an increase in inbreeding in the last few years for this population.

\subsection{Inbreeding Coefficient Trends}

Figure 1 shows Fped and Fmg's trends for the years from 2005 to 2017. Although the trends are similar in both, the annual change of Fped is not statistically significant $(p>0.05)$ with a coefficient of determination $\left(\mathrm{r}^{2}\right)$ of 0.45 , different from the coefficient of determination $\left(\mathrm{r}^{2}\right)$ for Fmg which was 0.76 . The differences in trends and the coefficient of determination are related to the low correlation between Fped and Fmg which was 0.41.

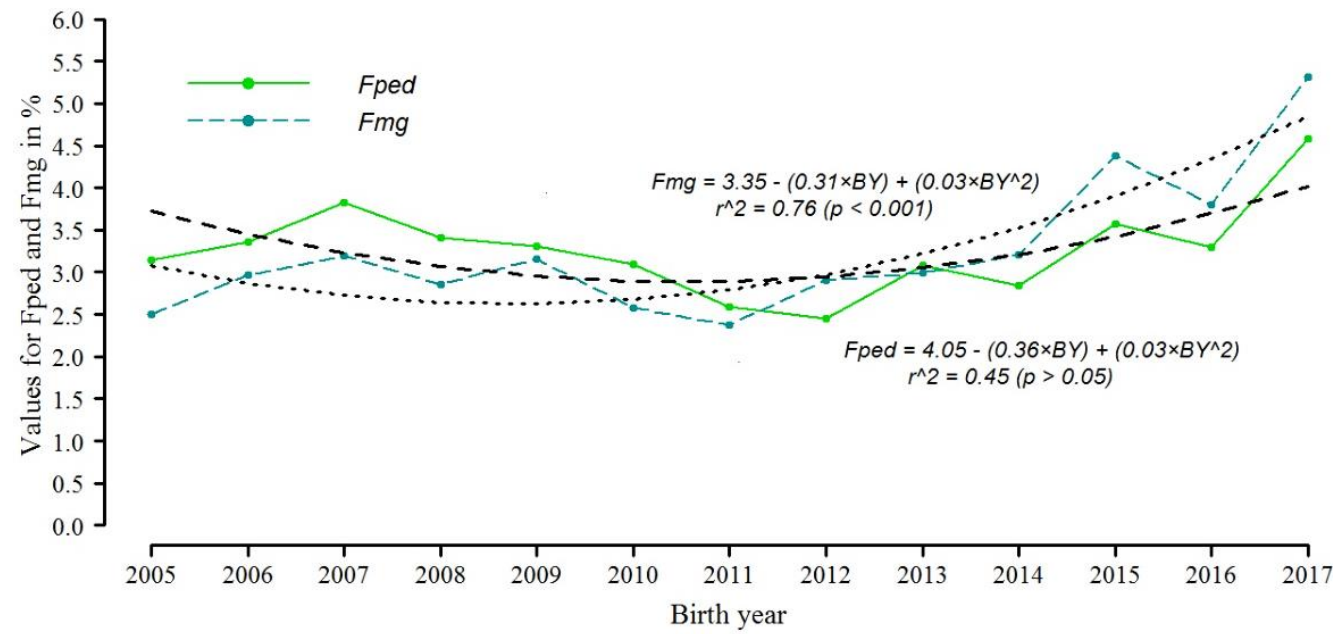

Figure 1. Distribution of inbreeding coefficients calculated through pedigree (Fped) and calculated through genomic relationship matrix (Fmg), from 2005 to 2017, with trends lines. BY: Birth year recoded from 1 to 13, BY^2: Squared recoded birth year. 
Figure 2 illustrates the annual accumulation of inbreeding measured by Froh and Fgeno. Although the correlation between Froh and Fgeno was high (0.82), the trend lines are dissimilar, with $r^{2}=0.83$ for Froh and $2.08 r^{2}=0.75$ for Fgeno. The high correlation between Fgeno and Fmg $(0.96)$ and similar slopes to $B_{1}(-0.41$ and -0.31 respectively) were expected because both use frequencies of homozygous SNP markers and heterozygotes.

Considering that the correlation between Froh based on large $\mathrm{ROH}$ and other $\mathrm{F}$ measures was higher than the other lengths (Table 3), and that this Froh is associated with recent inbreeding, it follows that the recent -inbreeding increase in Fgeno and Fmg should be expected.

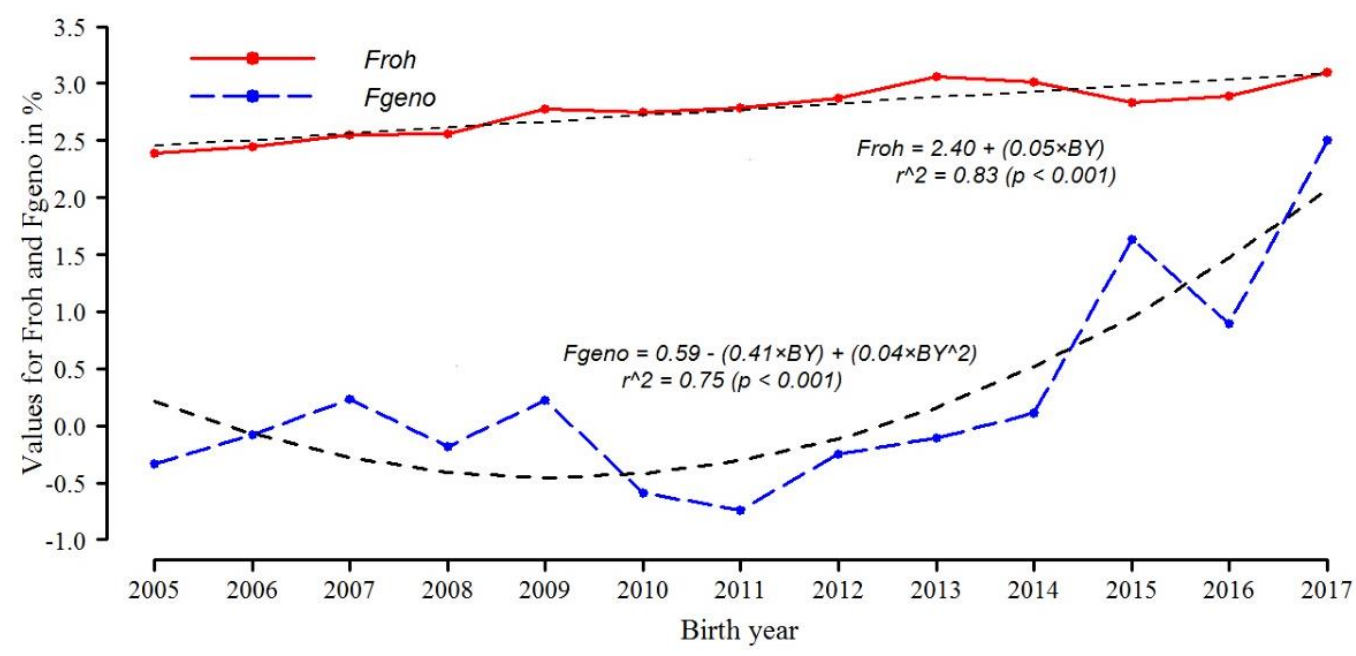

Figure 2. Distribution of inbreeding coefficients calculated by Runs of Homozygosity (Froh) and calculated by the number of homozygotic SNP markers observed and expected (Fgeno), from 2005 to 2017, with trend lines. BY: Birth year recoded from 1 to 13, BY^2: Squared recoded birth year.

\section{Conclusions}

In small populations, inbreeding based on genomic information is consistent among the different estimates, however, their correlation with Fped is low. Nevertheless, Froh and Fgeno supply additional information such as how far back inbreeding was present in the population. In this study, Froh showed recent inbreeding in the Mexican Holstein population and Fgeno showed the possibility that the ancestors of the evaluated animals had been mated with animals of different breeds or with animals genetically distant. Froh presented higher correlations with the other inbreeding coefficients as the length of the $\mathrm{ROH}$ increased. Finally, differences were observed between the ancestor's countries of origin regardless of the method of calculating the inbreeding coefficient.

Author Contributions: Data curation, J.C.-H., F.d.J.R.-L. and A.G.-R.; Formal analysis, J.C.-H. and A.G.-R.; Funding acquisition, F.d.J.R.-L. and A.G.-R. Investigation and Methodology, J.C.-H., F.d.J.R.-L., C.G.V.-P. and A.G.-R.; Writing original draft, J.C.-H., Writing-review and editing and supervision, F.d.J.R.-L., C.G.V.-P. and A.G.-R. All authors have read and agreed to the published version of the manuscript.

Funding: This study was funded by the project "Study of inbreeding and its effect on productive and reproductive features in Holstein cattle. No. SIGI: 11513634465" of the CENIDFyMA, INIFAP.

Acknowledgments: To the Asociación Holstein de México, for the information supplied.

Conflicts of Interest: The authors declare no conflict of interest. The funders had no role in the design of the study; in the collection, analyses, or interpretation of data; in the writing of the manuscript, or in the decision to publish the results. 


\section{References}

1. López-Gatius, F. Factors of a noninfectious nature affecting fertility after artificial insemination in lactating dairy cows. A review. Theriogenology 2012, 77, 1029-1041. [CrossRef]

2. Wiggans, G.R.; Cole, J.B.; Hubbard, S.M.; Sonstegard, T.S. Genomic Selection in Dairy Cattle: The USDA Experience. Annu. Rev. Anim. Biosci. 2016, 5, 309-327. [CrossRef]

3. Rodríguez-Ramilo, S.T.; Fernández, J.; Toro, M.A.; Hernández, D.; Villanueva, B. Genome-Wide estimates of coancestry, inbreeding and effective population size in the Spanish Holstein Population. PLoS ONE 2015, 10, e0124157. [CrossRef]

4. Pryce, J.E.; Haile-mariam, M.; Goddard, M.E.; Hayes, B.J. Identification of genomic regions associated with inbreeding depression in Holstein and Jersey dairy cattle. Genet. Sel. Evol. 2014, 46, 1-14. [CrossRef]

5. Mastrangelo, S.; Tolone, M.; Gerlando RDi Fontanesi, L.; Sardina, M.T.; Portolano, B. Genomic inbreeding estimation in small populations: Evaluation of runs of homozygosity in three local dairy cattle breeds. Anim. Consort. 2016, 10, 746-754. [CrossRef] [PubMed]

6. Wright, S. Coefficients of Inbreeding and Relationship. Am. Nat. 1922, 56, 330-338. Available online: https://www.jstor.org/ stable/2456273 (accessed on 7 September 2021). [CrossRef]

7. Guitou, H. Coeficiente de consanguinidad de un individuo. Sistemas de apareamiento. Rev. Angus 2010, 248, 31-37.

8. Mcquillan, R.; Leutenegger, A.; Abdel-rahman, R.; Franklin, C.S.; Pericic, M.; Barac-lauc, L.; Smolej-Narancic, N.; Janicijevic, B.; Polasek, O.; Tenesa, A.; et al. Runs of Homozygosity in European Populations. Am. J. Hum. Genet. 2008, 83, 359-372. [CrossRef]

9. Rebelato, A.B.; Caetano, A.R. Runs of homozygosity for autozygosity estimation and genomic analysis in production animals. Pesqui. Agropecuária Bras. 2018, 53, 975-984. [CrossRef]

10. Aguilar, I.; Misztal, I.; Legarra, A.; Tsuruta, S. Efficient computation of the genomic relationship matrix and other matrices used in single-step evaluation. J. Anim. Breed. Genet. 2011, 128, 422-428. [CrossRef] [PubMed]

11. Purfield, D.C.; Berry, D.P.; Mcparland, S.; Bradley, D.G. Runs of Homozygosity and Population History in Cattle. BMC Genet. 2012, 13, 2-11. Available online: http:/ / www.biomedcentral.com/1471-2156/13/70\%0ARESEARCH (accessed on 5 June 2021). [CrossRef]

12. Kim, E.-S.; Sonstegard, T.S.; Van Tassell, C.P.; Wiggans, G.; Rothschild, M.F. The Relationship between Runs of Homozygosity and Inbreeding in Jersey Cattle under Selection. PLoS ONE 2015, 10, e0129967. Available online: http:/ /www.pubmedcentral.nih. gov / articlerender.fcgi?artid=PMC4496098 (accessed on 10 November 2021). [CrossRef] [PubMed]

13. Ferenčaković, M.; Hamzić, E.; Gredler, B.; Solberg, T.R.; Klemetsdal, G.; Curik, I.; Sölkner, J. Estimates of autozygosity derived from runs of homozygosity: Empirical evidence from selected cattle populations. J. Anim. Breed. Genet. 2013, 130, $286-293$. [CrossRef]

14. Tier, B.; Meyr, K.M.F. Which Genomic Relationship Matrix? In Proceedings of the 21st Conference of the Association for the Advancement of Animal Breeding and Genetics, Lorne, Australia, 28-30 September 2015; pp. 28-30. Available online: https:/ / hdl.handle.net/1959.11/19010 (accessed on 10 November 2021).

15. Lozada-Soto, E.A.; Maltecca, C.; Lu, D.; Miller, S.; Cole, J.B.; Tiezzi, F. Trends in genetic diversity and the effect of inbreeding in American Angus cattle under genomic selection. Genet. Sel. Evol. 2021, 53, 1-15. [CrossRef] [PubMed]

16. Boichard, D. Pedig: A fortran package for pedigree analysis suited for large populations. In Proceedings of the 7th World Congress on Genetics Applied to Livestock Production, Montpellier, France, 19-23 August 2002. Available online: https: / / hal.inrae.fr/hal-02833573/document (accessed on 10 November 2021).

17. Aguilar, I.; Misztal, I. Technical note: Recursive algorithm for inbreeding coefficients assuming nonzero inbreeding of unknown parents. J. Dairy Sci. 2008, 91, 1669-1672. [CrossRef]

18. VanRaden, P.M.; O'Connell, J.R.; Wiggans, G.R.; Weigel, K.A. Genomic evaluations with many more genotypes. Genet. Sel. Evol. 2011, 43, 10. [CrossRef] [PubMed]

19. Kirin, M.; McQuillan, R.; Franklin, C.S.; Campbell, H.; McKeigue, P.M.; Wilson, J.F. Genomic runs of homozygosity record population history and consanguinity. PLOS ONE 2010, 5, e13996. Available online: http://www.pubmedcentral.nih.gov/ articlerender.fcgi?artid=PMC2981575 (accessed on 10 November 2021). [CrossRef]

20. Van Raden, P.M.; Olson, K.M.; Wiggans, G.R.; Cole, J.B.; Tooker, M.E. Genomic Inbreeding and Relationships among Holsteins, Jerseys, and Brown Swiss. J. Dairy Sci. 2011, 94, 5673-5682. Available online: http://www.ncbi.nlm.nih.gov/pubmed/22032391 (accessed on 20 October 2021). [CrossRef]

21. Bjelland, D.W.; Weigel, K.A.; Vukasinovic, N.; Nkrumah, J.D. Evaluation of inbreeding depression in Holstein cattle using whole-genome SNP markers and alternative measures of genomic inbreeding. J. Dairy Sci. 2013, 96, 4697-4706. [CrossRef]

22. Aguilar, I.; Misztal, I.; Tsuruta, S.; Legarra, A. PREGSF90-POSTGSF90: Computational Tools for the Implementation of Single-step Genomic Selection and Genome-wide. In Proceedings of the 10th World Congress of Genetics Applied to Livestock Production PREGSF90, Vancouver, BC, Canada, 2014; p. 3. Available online: https://www.researchgate.net/publication/264973897\% OAPREGSF90 (accessed on 10 November 2021).

23. Golden Helix, I.; Bozeman, M. SNP E Variation Suite ${ }^{T M}$; (Version 8) [Software]; Golden Helix, Inc.: Bozeman, MT, USA; p. 8. Available online: https://www.goldenhelix.com/products/SNP_Variation/index.html (accessed on 10 November 2021).

24. Wayne, W.D. Bioestadística: Base Para el Análisis de las Ciencias de la Salud, 4th ed.; Wayne, W.D., Ed.; Editorial Limusa, S.A. De C.V.: Limusa, México, 2017; pp. 400-474. 
25. SAS Institute. 2019. Available online: https://www.sas.com/es_mx/industry/life-sciences/solution/real-world-evidence.html (accessed on 10 November 2021).

26. Vargas Rodríguez, Y.M.; Eduardo, A.; Valdivia, O.; Rodríguez, G.I.V. Regresión polinómica, una competencia indispensable para el tratamiento de datos en Cinética Química. ContactoS 2015, 98, 25-35. Available online: https://apprimac.com/wp-content/ uploads/2019/07/regresion_polinomica.pdf (accessed on 1 November 2021).

27. R Core Team. R: A Language and Environment for Statistical Computing; R Foundation for Statistical Computing: Vienna, Austria, 2019. Available online: https://www.r-project.org/ (accessed on 1 November 2021).

28. Marras, G.; Gaspa, G.; Sorbolini, S.; Dimauro, C.; Ajmone-marsan, P.; Valentini, A.; Williams, J.L.; Macciotta, N.P. Analysis of runs of homozygosity and their relationship with inbreeding in five cattle breeds farmed in Italy. Anim. Genet. 2014, 46, 110-121. [CrossRef]

29. Zhang, Q.; Calus, M.P.L.; Guldbrandtsen, B.; Lund, M.S.; Sahana, G. Estimation of inbreeding using pedigree, 50k SNP chip genotypes and full sequence data in three cattle breeds. BMC Genet. 2015, 16, 1-11. [CrossRef]

30. Forutan, M.; Ansari Mahyari, S.; Baes, C.; Melzer, N.; Schenkel, F.S.; Sargolzaei, M. Inbreeding and runs of homozygosity before and after genomic selection in North American Holstein cattle. BMC Genom. 2018, 19, 1-12. [CrossRef]

31. Szmatoła, T.; Gurgul, A.; Ropka-Molik, K.; Jasielczuk, I.; Zabek, T.; Bugno-Poniewierska, M. Characteristics of runs of homozygosity in selected cattle breeds maintained in Poland. Livest Sci. 2016, 188, 2-80. [CrossRef]

32. García-Ruiz, A.; Ruiz-Lopez, F.J.; Wiggans, G.R.; Van Tassell, C.P.; Montaldo, H.H. Effect of reference population size and available ancestor genotypes on imputation of Mexican Holstein genotypes. J. Dairy Sci. 2015, 98, 3478-3484. [CrossRef]

33. Meuwissen, T.H.E.; Sonesson, A.K.; Gebregiwergis, G.; Woolliams, J.A. Management of Genetic Diversity in the Era of Genomics. Front. Genet. 2020, 11, 1-16. [CrossRef]

34. Makanjuola, B.O.; Miglior, F.; Abdalla, E.A.; Maltecca, C.; Schenkel, F.S.; Baes, C.F. Effect of genomic selection on rate of inbreeding and coancestry and effective population size of Holstein and Jersey cattle populations. J. Dairy Sci. 2020, 103, 5183-5199. [CrossRef]

35. Caballero, A.; Villanueva, B.; Druet, T. On the estimation of inbreeding depression using different measures of inbreeding from molecular markers. Evol. Appl. 2021, 14, 416-428. [CrossRef] [PubMed]

36. Gurgul, A.; Szmatoła, T.; Topolski, P.; Jasielczuk, I.; Żukowski, K.; Bugno-Poniewierska, M. The use of runs of homozygosity for estimation of recent inbreeding in Holstein cattle. J. Appl. Genet. 2016, 57, 527-530. [CrossRef] [PubMed]

37. Villanueva, B.; Fernández, A.; Saura, M.; Caballero, A.; Fernández, J.; Morales-González, E.; Toro, M.A.; Pong-Wong, R. The value of genomic relationship matrices to estimate levels of inbreeding. Genet. Sel. Evol. 2021, 53, 1-17. [CrossRef]

38. Andere, C.I.; Rubio, N.; Rodriguez, E.; Casanova, D.; Aguilar, I. Inbreeding analysis of the population of Holstein dairy cattle registered in the Official Milk Control System of the Argentine Republic. Rev. Investig. Agropecu. 2017, $43,92-97$.

39. García-Ruiz, A.; Cole, J.B.; VanRaden, P.M.; Wiggans, G.R.; Ruiz-López, F.J.; Van Tassell, C.P. Changes in genetic selection differentials and generation intervals in US Holstein dairy cattle as a result of genomic selection. Proc. Natl. Acad. Sci. USA 2016, 113, E3995-E4004. [CrossRef] [PubMed] 